\title{
Reconocimientos, trayectos y engaños: reflejos literarios de la emergencia del cine en Santiago de Chile (1900-1931)'
}

\section{Recognitions, Paths and Deceits: Literary Reflections on the Emergence of Cinema in Santiago (1900-1931)}

\author{
Javiera Lorenzini Raty \\ Universidad de Chile, Chile \\ javieralorenzini@gmail.com
}

\section{Resumen:}

En este trabajo se rastrearán las huellas "imaginarias" de la emergencia del cine en Santiago de Chile en tres textos literarios de la época: Casa Grande, de Luis Orrego Luco; la serie de crónicas "Un roto va al cine" y "La visita del cowboy", de Joaquín Edwards Bello. Desde el marco metodológico aportado por la historia cultural urbana, el análisis de estas obras pretende constatar el modo en que el impacto representacional del fenómeno cinematográfico en Santiago de inicios de siglo xx permite entrever un espacio público cruzado por ambigüedades y tensiones discursivas.

Palabras clave: Santiago de Chile, cine, reflejos literarios, historia cultural urbana.

\section{Abstract:}

The following article will trace, in three literary texts, the "imaginary" footprints of the appearance of the cinema in Santiago, Chile: Casa Grande by Luis Orrego Luco, and the chronicles "Un roto va al cine" and "La visita del cowboy" by Joaquín Edwards Bello. From the methodological framework given by the history of urban culture, the analysis of these texts will try to ascertain how the representational impact of the cinematographic phenomenon in Santiago, during the 20th century, articulates a public space characterized by discursive tensions and ambiguities.

Keywords: Santiago de Chile, Cinema, Literary Reflections, Urban Culture.

1 Este trabajo fue escrito en el marco del Proyecto Fondecyt regular 1095210: "Reflejos y reflexiones del cine en discursos literarios, artísticos, periodísticos y sociológicos en Chile entre 1900 y 1940”, dirigido por el dr. Wolfgang Bongers. Una versión previa y reducida del mismo fue presentado en el marco del Segundo Encuentro de Investigadores de la Cineteca Nacional, en el año 2012, a partir del cual recogí valiosas sugerencias que se incorporan en la versión definitiva de este estudio. 
El cine se adelantó a la modernización. Llegó décadas antes que los rascacielos, casi al mismo tiempo que el tranvía más antiguo, cuando Santiago aún destilaba apatía colonial. Si en 1927, sacudidos ya los resabios del parlamentarismo, sería recién cuando los santiaguinos pudiesen conocer verdaderas reformas modernizadoras que integrarían a la capital como un todo -desconociendo la habitual división entre la "ciudad oficial" del casco histórico y la aristocracia, y la "ciudad no oficial", del proletariado y el conventillo-, las modernas imágenes de la pantalla ya desde principios del siglo xx eran proyectadas de la periferia hacia el centro de Santiago.

Una revisión de los procesos que involucró la llegada del cine a la capital ${ }^{2}$ lleva a ciertas conclusiones que se vuelcan, así, en contra del sentido común: el cine no fue un aspecto (entre otros) de la modernización de Santiago, sino un importante antecedente. Como la primera manifestación de una cultura de masas que se presenció y se hizo presente no solo en el casco histórico sino a lo largo de toda la capital, el fenómeno cinematográfico prefiguró su integración ${ }^{3}$ y la unificación de la vivencia de un tiempo histórico compartido entre los habitantes del centro y la periferia. A partir de la ciudad imaginaria de la pantalla se comenzó a acumular un patrimonio simbólico común que se acopló de manera particular a las necesidades y carencias propias del contexto local, un Santiago inmerso en una profunda crisis. Las imágenes de la moderna metrópolis norteamericana, que desde la década de 1920 ya importaban de modo casi exclusivo las películas hollywoodenses, aportaron nuevas maneras de pensar la ciudad en términos urbanos, arquitectónicos y sociales. La "ciudad futura" que los espectadores santiaguinos vieron en el cine las primeras tres décadas del siglo xx sería determinante en la configuración del imaginario reflejado en el proyecto de modernización nacionalista de lbáñez.

En este marco, me interesa trabajar el período previo a estas reformas urbanas, entre 1896 y 1927, en que el desfase entre la ciudad imaginaria (representacional) y la ciudad real va a devenir en la aparición y tránsito de nuevos discursos, que materializan el dinamismo entre las viejas representaciones (la ciudad patricia segregada y en crisis del período parlamentario) y las nuevas (la moderna ciudad de las películas estadounidenses). La coyuntura que significó el cruce entre la ciudad "umbral” y el cine como fenómeno “umbral” va a generar, asimismo, discursos “umbrales". Algunos de estos discursos serán los que se analizaré en tres textos literarios de la época, adscribiendo al manejo de nuevas fuentes al que la historia cultural urbana ${ }^{4}$-a la que me vinculo- recurre para dar cuenta de dichas representaciones.

2 Véase mi estudio "Huellas, umbrales y ciudades posibles: el fenómeno cinematográfico en Santiago" en Bifurcaciones 11 (2012), que aporta el marco necesario de comprensión para el análisis que se lleva a cado en este trabajo.

3 Véanse los dos últimos tomos de Historia de las ideas y la cultura en Chile, de Bernardo Subercaseaux (Santiago: Editorial Universitaria, 2004).

4 Para un estudio de la historia cultural a modo general, véase el libro de Peter Burke, ¿Qué es la historia cultural? Barcelona: Paidós, 2006. Para el caso particular de la historia cultural urbana revísese el capítulo "Consideraciones preliminares" del libro de Arturo Almandoz, La ciudad en el imaginario venezolano. Tomo l: Del tiempo de Maricastaña a la masificación de los techos rojos. Caracas: Fundación para la cultura urbana, 2002. 
Escribe Pablo Faúndez, respecto de la apropiación del cine por la literatura chilena, que: se da un fenómeno del todo singular: al tiempo que el cine chileno de aquellos años se sumó igualmente a la representación de estos tópicos nacionalistas, desde un enfoque narrativo asociable al naturalismo, la representación del cine en la literatura (aunque sería más correcto hablar de una presentación) fue ejercicio casi exclusivo del movimiento vanguardista en el escenario nacional (211).

Si bien la llegada del cine a Santiago puede, y ha sido, estudiada predominantemente en los textos de vanguardia (los proyectos casi opuestos de Huidobro y De Rokha, entre otros) ${ }^{5}$, esta revisión se alejará de ese corpus para incursionar en otras relecturas cinematográficas menos visitadas: Casa Grande, de Luis Orrego Luco, la serie de crónicas “Un roto va al cine”, de Montecristo y “La visita del cowboy”, crónica de Joaquín Edwards Bello. Así se matizará lo afirmado por Faúndez, para descubrir las ambigüedades discursivas explicitadas por la mirada cosmopolita del cine en el terreno mismo de una literatura que, cuanto más alejada de los quiebres y provocaciones vanguardistas, reflejará mejor estas movilidades y desencuentros.

\section{El engaño y el cine en Casa Grande}

Los ambientes urbanos en Casa Grande, la polémica novela publicada por Luis Orrego Luco en 1908, nos presentan un espacio público que, pese a reducirse a la ciudad oficial (esto es, el casco histórico) presenta las características propias de la ciudad umbral. Así, por ejemplo, la escena que abre la novela describe el siguiente cuadro:

en la muy leal y pacífica ciudad de Santiago, un tanto sacudida de su apatía colonial [...] corrían los coches haciendo saltar las piedras. Los tranvías, completamente llenos, con gentes de pie sobre las plataformas, parecían anillos luminosos de colosal serpiente asomada a la calle del Estado (7).

Este y otros panoramas de la obra presentan la casa grande que es Santiago aún erguida con sus grandes habitaciones coloniales pero al mismo tiempo remodelada "a la moderna, con lámparas de gas aceltileno, sala de billares y espléndida capilla” (23). Reflejando esta época de cruces ideológicos y ambigüedades urbanas, Casa Grande se desarrolla como una obra en que la tesis naturalista (anacrónica por cierto) aparece trastocada por la modernidad6.

Entre estas irrupciones modernas, en la novela de Orrego Luco podemos encontrar el fenómeno cinematográfico explícitamente tematizado en una de las escenas fundamentales del libro. Así, se relata en el quinto capítulo de Casa Grande que la noche en que Gabriela Sandoval y Ángel Heredia, sentados en un asiento rústico en la hacienda familiar,

5 Cfr. Faúndez, Pablo. "El cine en las letras chilenas de principios de siglo: otra discusión sobre la vanguardia". Taller de Letras 46 (2010).

6 Como explicita Lucía Guerra, el desborde de la novela de tesis aparece evidenciada, entre otros, en la cinematográfica locura de Ángel: su mujer muerta y su amante se doblan y superponen en la pesadilla que cierra el libro. 
se besaron por primera vez y sellaron así un melodramático destino-que bien habría podido ser cinematográfico-, su padre había ofrecido una gran fiesta a los inquilinos y pobres del gran fundo santiaguino, en el que se brindó un extraño espectáculo:

En el vestíbulo funcionaba el cinematógrafo, proyectando sus cuadros sobre una gran tela blanca. La gente del pueblo contemplaba aquello maravillada, creyéndolo cosa de brujería, por lo cual se santiguaba apresuradamente.

- Ben haiga, hijita -decía una vieja- estas funcias de parecíos...

- No se le dé naa, comadre -respondía otra- que son los patrones vestíos de farsa que saltan pal otro lao... (Orrego Luco 53).

Este es el primero entre otros pasajes de Casa Grande en que se presenta el cruce entre hábitos coloniales santiaguinos y el nuevo invento del cinematógrafo. El leve anacronismo de la escena, presentado como "cosa de brujería”, es el espejo de esta época en la que novedosas tecnologías impactan los modos de vivir conocidos, creando nuevas zonas de realidad que exigen de quienes les toca vivirlas -en este caso, a las viejas del bajo pueblo- un re-conocimiento del mundo y de sí mismas. Las viejas miran en la pantalla estos "parecíos" que sin embargo no son verdaderos; son una "farsa", un engaño. En efecto, los patrones, "vestíos de farsa" las están engañando, y eso es perceptible precisamente en la proyección: en el lugar umbral de la pantalla la ciudad comienza a verse a sí misma.

La "farsa" descubierta por las viejas espectadoras es la misma "farsa" hecha manifiesta por Luis Orrego Luco a lo largo de la novela, que retrata los vicios de una clase dirigente que antepone el lucro a principios morales y sociales. Este engaño que, descubierto, es el del fracaso de un sistema político, tiene su correspondencia con la "farsa" del beso entre Gabriela Sandoval y Ángel Heredia, cuya unión se va a constituir como el fracaso alegórico fundamental del libro. Así, si seguimos la línea expuesta por Doris Sommer (2004) en su libro Ficciones Fundacionales, el fracaso del matrimonio entre los protagonistas sería la representación alegórica de las exclusiones propias de la esfera política. Como explica la autora, en América Latina del siglo xIX:

[I]as novelas se desarrollan mano a mano con la historia patriótica [...] Juntas despertaron un ferviente deseo de felicidad doméstica que se desbordó en sueños de prosperidad nacional materializándose en proyectos de construcción de naciones que invistieron a las pasiones privadas con objetivos públicos (23).

Todas estas novelas fundacionales tendrían como eje una historia de amor con final feliz que, como en Martín Rivas, representa no solo la conciliación de los amantes sino de diferentes sectores sociales bajo un discurso hegemónico unificador. En Casa Grande, por el contrario, es premonitorio que el quiebre de la relación de la pareja esté precisamente dado por el enamoramiento de Ángel de una norteamericana, Nelly. Este final es el que frustra la promesa (matrimonial y política/social) del beso entre Gabriela Sandoval y Ángel Heredia, escena que sigue precisamente a la constatación de la "farsa" que hacen las señoras del pueblo en el capítulo v de la obra. Este capítulo, en tanto comienza y termina con dos escenas cinematográficas -ambos fragmentos que muestran al pueblo impresionado con el espectáculo que brindan sus patrones-, puede considerarse 
en el marco de este trabajo como aquél que es precisamente cinematográfico. Los dos pasajes en que aparece el nuevo invento funcionan como soporte y marco narrativo al acontecimiento fundamental que es el beso entre Ángel y Gabriela. Mientras "tempestad de gritos, exclamaciones y gestos de sorpresa saludaban a la aparición de cada escena" (Orrego Luco 54), la pareja se distancia del ruido y de la muchedumbre para protagonizar la declaración de amor. Llanto, rubores, incluso un beso (que probablemente habría sido considerado "inconveniente para señoritas" por la censura cinematográfica de la época), nada falta en este cuadro melodramático en que los protagonistas se visten de farsa para sellar su destino trágico. El ojo de la "cámara narrativa" sigue entonces de vuelta a los amantes para terminar enfocando el lugar donde comenzó la escena y termina el capítulo:

Y luego echaron a correr, cada uno por su lado, despidiéndose: "hasta siempre..."

[...] La gente del pueblo, el inquilinaje, las mujeres y niños los recibían con vivas y exclamaciones de placer. El cinematógrafo comenzaba las 'escenas de una cacería en África'; el entusiasmo del pueblo rayaba en el delirio al ver a un boer corriendo a galope tendido y con el lazo en la mano (57).

Bien podría considerarse, ya habiendo revisado la estructura del capítulo, que no se llega a la escena del beso entre Ángel y Gabriela desplazándose espacialmente al interior del fundo sino que adentrándose en la pantalla, y que esta es precisamente la "farsa" que observan y denuncian las dos viejecitas al comienzo del capítulo. La ciudad patricia en crisis-representada por la casa colonial y por el fracaso de los amantes-se ve así enmarcada y re-conocida por esta otra nueva manera de comprender el mundo que entrega el cinematógrafo, cuyo lente permite detectar la "farsa" que es, según lo que ya hemos constatado, una larga historia de exclusiones.

No son estas las únicas referencias al cinematógrafo que existen en Casa Grande. A lo largo del siguiente capítulo, los personajes vuelven a disfrutar de las vistas animadas. Este detalle pasa para muchos de sus lectores de hoy completamente desapercibido, tal como el espectador olvida el soporte de la película en la que está inmerso. No les ocurre lo mismo a los personajes del libro, que en el marco de estas nuevas zonas de realidad pueden re-conocer su ciudad en sus "farsas" y en sus potencialidades, en su condición intermedia entre la ciudad colonial y la nueva ciudad inclusiva y moderna. El quiebre entre los amantes en Casa Grande se revierte en los finales felices de las películas hollywoodenses, no ya en casas grandes, sino en gigantes rascacielos.

\section{La crónica, el paseo y el umbral en la serie "Un roto va al cine"}

Varios años después de esta tematización del cine en Casa Grande aparecen las primeras revistas cinematográficas especializadas. A partir de 1915, el cine, que solo había tenido en Santiago un impacto discursivo esporádico -como anuncios ligado a otros espectáculos de variedades o en escenas aisladas como la que encontramos en Casa Grande- encuentra un lugar textual en estas publicaciones, en las que no solo se publicita el nuevo espectáculo 
sino que se lo intenta aprehender en tanto nuevo fenómeno artístico y social ${ }^{7}$. Inserta en estas revistas, la crónica cinematográfica aparece como un género desde el cual, si bien no se produce una crítica especializada, sí al menos se textualiza el nuevo espectáculo por parte de voces emergentes, que mediante una escritura muchas veces impresionista buscan acercar el cine a un público lector y espectador. impresionista buscan acercar el cine a un público lector y espectador.

Así, puede considerarse que la crónica, como género limítrofe entre la literatura y el periodismo, como poética débil que problematiza la oposición entre alta y baja cultura (149), constituye un espacio textual favorecido en la aprehensión del nuevo fenómeno cinematográfico, en tanto recoge, como se escribe en la introducción al capítulo "Crítica y Crónica" del libro Archivos i letrados, los "desechos" que no han sido considerados por la elite culta (y entre los cuales figura el cine):

en relación al eje cine-escritura es sugerente establecer cómo la crónica en tanto espacio escritural dispuesto a la contaminación se habría visto envuelta en otro tipo de impureza al conjugarse con la temática cinematográfica. Esto, en la medida que el cine se configura como un medio que pone en entredicho el binarismo alta/baja cultura, y que desde sus inicios hasta la contemporaneidad, se ha comprendido como un arte impuro (265) 8 .

La crónica como género contingente y flexible, abierto al ensayo y a la digresión impresionista, es un lugar que permite la textualización de la novedad del cine y que comienza a familiarizar a sus lectores con el nuevo invento en el seno de una muy incipiente industria cultural. Esta naturalización del novedoso espectáculo que llevan a cabo las nuevas revistas especializadas puede entenderse, escribe Julio Ramos (2003), como una estrategia de rearticulación del espacio público que ha sido disgregado por los sucesivos embates de la modernidad. La ansiedad que genera en los habitantes de Santiago este período de progresivos cambios requiere de la "producción de imágenes reorganizadoras de los discursos de la ciudad" (162), que en el caso de la crónica re-narrativizan no solo lo fragmentario de la disposición gráfica de la revista sino también de la urbe.

Así, se va constatando en las distintas (y en muchos casos efímeras) revistas especializadas de cine que surgen a partir de 1915 el impacto representacional del nuevo espectáculo, desde la subjetividad de cada uno de los cronistas que se pasean por Santiago. Un caso particular lo constituye una serie de crónicas escrita en la revista Mundo Teatral bajo el seudónimo de Montecristo ${ }^{9}$, publicadas sucesivamente entre octubre y noviembre de 1919 con los títulos "Un roto en el Splendid", "Un roto en el Alhambra”, “Un roto en

7 Cfr. Bongers, Wolfgang. "El cine y su llegada a Chile: conceptos y discursos”. En Taller de Letras 46 (2010) y Ossandón, Carlos y Eduardo Santa Cruz. El estallido de las formas. Chile en los albores de la "cultura de masas". Santiago: LOM Ediciones, 2005.

8 En esta introducción caracteriza a la crónica cinematográfica como un discurso doblemente impuro, en tanto reúne la ambigüedad textual propia del género cronístico y aquella otra impureza que André Bazin le atribuye al cine como arte donde se cruzan otras manifestaciones artísticas como el teatro y la literatura (105).

9 Si bien no se conoce qué autor pudo estar tras el seudónimo, si es bastante evidente que este hace referencia a una película que era muy popular en la época, El conde de Montecristo. 
el Unión Central” y “Un roto en el Brasil”10. Las crónicas relatan, en una serie de cuadros costumbristas, las visitas que hace un "roto chileno" a cuatro cines de Santiago, y los diferentes avatares que vive en cada uno de ellos: los problemas que tiene para entrar a cada una de las funciones, las personas con las que se encuentra al interior de los biógrafos y las películas que ve. Presentando un formato de guión que, en consideración del tema de las crónicas, bien podemos calificar como cinematográfico, el lector presencia el diálogo jocoso de José Menchi (el roto) y Ña Zoila:

José Menchi: Sí, comaire por la serpiente en coche, le iré que me estoy sintiendo despeutar de teatros; como había oído hablar del Brasil onde un tal Rafael Frantaura hace monos con los pies y aonde toa la gallá es brasilera, me las eché p'allá pus, qu'iba hacer: yo tenía que ver el bolaco.

La comarie Zoila: El Brasil ¿dice compaire? Qué no es un imperio que está relejos? José Menchi: Taba relejos pus comaire, pero on Peiro Montt, el presidente trigueñito y cerrado de barba, lo trajo pa Santiago con emperaor y too.

Como este, otros diálogos cómicos de José Menchi con distintos personajes se suceden a lo largo de las cuatro crónicas enmarcadas en el contexto novedoso de la visita al biógrafo. La reproducción del habla popular y el humorismo como lugares comunes asociados a lo que debe ser una correcta escenificación del "roto", figura que en la época ya es tratada como símbolo de lo nacional, se ven permeados por ciertos referentes foráneos traídos por el cine, como por ejemplo -en el caso de las crónicas que nos ocupanel vagabundo Charlie Chaplin, según explicita Consuelo Vargas ${ }^{11}$. De la misma manera, la presentación que se hace en la crónica de distintos personajes locales (el "paco", el "boletero", etc.) aparece permeada por la introducción del nuevo espectáculo foráneo, que inaugura espacios para nuevos sujetos como los que retrata el "roto" José Menchi en cada uno de sus paseos al cine.

En el recorrido del personaje por diferentes teatros destaca la elaboración de un discurso cronístico/itinerante que incorpora al cine como eje articulador de Santiago; si como escribe Ramos "[e]l paseo ordena, para el sujeto, el caos de la ciudad, estableciendo articulaciones, junturas, puentes, entre espacios (y acontecimientos) desarticulados” (165), el paseo del roto, al inscribirse en el casco histórico de la ciudad, representa una incursión desde la periferia al centro y por lo tanto del espacio físico del cine como lugar integrador ${ }^{12}$.

10 El nombre de esta serie, que podría resumirse bajo el nombre "Un roto va al cine", tiene su correspondencia curiosa en un texto citado por Gonzalo Aguilar (2009) titulado "Un gaucho va al cine”, en el que se juega también con los cruces entre el ojo cosmopolita de la cámara y el símbolo nacional argentino del gaucho (159).

11 Observa Vargas que las bufonadas chaplinescas - muy populares en aquella época- asociadas a la construcción del personaje nacional de "roto son una entre tantas "paradojas cosmopolitas" que provoca la emergencia del fenómeno cinematográfico en Chile (50).

12 Esta naturalización del novedoso espectáculo que llevan a cabo las nuevas revistas especializadas puede entenderse, escribe Julio Ramos, como una estrategia de rearticulación del espacio público que ha sido disgregado por los sucesivos embates de la modernidad. La ansiedad que genera en los habitantes de Santiago este período de progresivos cambios requiere de la "producción de imágenes reorganizadoras de los discursos de la ciudad” (Ramos 162), que en el caso de la crónica re-narrativizan no solo lo fragmentario de la disposición gráfica de la revista sino también de la urbe. 
En efecto, el roto visita los cines "delegantes" donde va "toa la gallá bien togá" e incluso las "cabritas" que, exclama luego haciendo un juego de palabras con el nombre del cine, "sí que son splendi".

Esta incursión del pícaro roto en los teatros más caros no es, sin embargo, del todo fácil. De ahí que a lo largo de las cuatro crónicas que componen la serie, el roto se encuentre siempre a medio camino entre el afuera y el adentro del cine (precisamente: en el umbral), frecuentemente detenido por quienes no encuentran adecuada su presencia en tan distinguido espectáculo. Así, José Menchi relata a Ña Zoila respecto de su visita al Alhambra:

José- Si, comaire, con el compaire Nolasco, me la eché pal Cine Alhambra. ... Dentremos le ije, ¿tiene mieo e parecer caballero? Si toos somos caballeros, eso si que sin plata. Se rió. Dentramos a platiá comaire, los costó 4 chulitos, si me hace el favor. ... Había harta gallá rebien chatre, caballeros toos, y me miraban con una cara e broma. Le ije a Nolasco, míreme compaire, como tengo la cara.

-Como toos los días, me ijo. Miré a los jutres, se reidan, me dio to la rabia y grité: -¿Qué m'están viendo monos en la cara? Si me sacan pica los agarro aletazos, porque soy roto gallo...

- ¿La saco? Me ijo Nolasco, (tiene una daga nuevecita)

-Echen pajuela este roto, sentí que decían. Ta borracho...

En todos los capítulos se desarrollan escenas de esta índole, en las que el roto, si bien concibe como posible su integración al mundo de los "caballeros", siempre se queda a medio camino, a punto de ser expulsado del teatro o emplazado en las peores ubicaciones. Nuevamente el habitante santiaguino (el roto) debe re-mirarse a sí mismo (la "cara e broma") para descubrir la burla de "estos jutres empaquetaos [que] andan triendo parches tapaos con las cuaraca"; esto es, nuevamente se devela la "farsa" que en las crónicas se vuelve cosa de juego entre la integración y la exclusión.

El juego contrastivo entre los "caballeros" y el "roto" se complica cuando aparece en escena el mismo Montecristo, cuyo nombre es el que firma la crónica. Situándose sutilmente a medio camino entre los "caballeros" (en tanto espectador culto) y el "roto" (a quien ayuda a entrar a los cines y por quién es caracterizado como "roto regallo"), el cronista Montecristo traza una sutil línea demarcatoria que, a una vez que incluye discursivamente al roto en el "chisme" localista, se separa de él, en una lógica que aúna inclusión y exclusión. Esa "curiosidad chismosa" que, según Ramos, lleva al acercamiento del cronista a un "otro", es también la delimitación de una frontera en la que el roto queda a medio camino: ni adentro ni afuera, en el umbral de la ciudad y de la escritura.

Esta dinámica de inclusiones y exclusiones escriturales no solo se ve potenciada por la elección de un género-la crónica-sino por el tema escogido. El motivo foráneo del cine, que parece en un primer momento ser utilizado como excusa para pintar un cuadro de costumbres locales, se vuelve-al igual que en el v capítulo de Casa Grande-el marco donde las escenas retratadas adquieren un dinamismo nuevo y una nueva ambigüedad. Así, en las crónicas se presencia la incorporación de nuevos sujetos a la trama urbana 
dominante y la acumulación de un patrimonio simbólico que es común a "caballeros" y "rotos". En efecto, tanto en el "Splendi" como en el "Seleuta" se pasan las mismas vistas a distintos precios, alega el roto José Menchi. A esta nueva inclusión, aunque simbólica, se agrega el lugar discursivo que se le otorga al roto para enunciar, al mismo tiempo que los recorre, nuevos discursos sobre Santiago.

\section{La locura por las estrellas en "La visita del cowboy"}

Otra serie de recorridos urbanos esboza una crónica que ya no podemos tildar de cinematográfica. "La visita del cowboy", texto publicado por Joaquín Edwards Bello en La nación en 1921, presenta el cuadro preciso de una locura particular: la que generaron las endiosadas estrellas hollywoodenses sobre los espectadores santiaguinos. El cronista relata cómo conoció a una criada, llamada Rosa Paiva, que deslumbrada por la perfección ilusoria de la vida de las stars pierde completamente la cordura.

La anécdota se articula a partir de la llegada de una carta misteriosa. El cronista comienza el texto relatando que "[h]ace pocos días charlábamos para la sobremesa en casa de un viejo amigo, cuando apareció un cartero que dejó una sola postal con sello de Nueva York, firmada Douglas Fairbanks. La dirección ponía Rosa Paiva, Recoleta, Santiago Chili" (Edwards Bello 217). La llegada de la carta misteriosa, primer gesto que muestra una extraña relación tendida entre la niña de la periferia y el rutilante actor, genera que el dueño de casa relate al cronista la historia de la niña. Ella, que había sido adoptada como sirvienta de la casa, conoce a los 12 años el cinematógrafo y queda completamente deslumbrada: la primera película que vio, de Douglas Fairbanks:

produjo una tremenda impresión en su ánimo. Esa noche durmió apenas; a cada momento despertaba viendo trágicas visiones, o alegres desenlaces, o amables cuadros de amor y del placer de vivir, todo ello inspirado en la película. (...) Al día siguiente, la vida le pareció mejor, pero su condición la llenó de dudas. Por primera vez se miró en el espejo con ojos escrutadores (Edwards Bello 217-18).

El autoescrutinio que hace la niña tras ver la película, gesto que se reitera en las escenas que hemos revisado en Casa Grande y en la serie "Un roto va al cine", en este caso implica el re-conocimiento de una "condición" ambigua que refiere tanto a unas carencias como a una fantasía ilusoria (el 'sueño americano'). Esto estimula en la niña el gusto por el fascinador espectáculo. Desde entonces, sigue el relato, Rosa fue al cine "dos veces por semana, los jueves y los domingos. Alguna vez llegó al Setiembre y hasta el lujoso y rutilante Alhambra" (218). Si bien sus preferidas eran las películas de cowboys-que, precisa el narrador, ella llamaba "combois"-, vio todos los filmes en cartelera y conoció en ellos a todas las estrellas famosas del momento. Mientras tanto, "[e]conomizaba dinero para irse a Norteamérica, tierra que era un interminable cuento azul, donde los aventureros son bonitos y las mujeres gastan un lujo indescriptible, y todo sale bien” (219) La fascinación por el starsistem es vivido por la niña como la contraposición entre dos lugares distintos: 
el mundo de la realidad y el mundo de las películas, que progresivamente se superponen a medida que Rosa cae definitivamente en una locura quijotesca. Ella genera una correlación directa entre el mundo soñado de las películas y la "azul" Norteamérica, a donde quiere viajar escapando del mundo real. Así, "[s]us ojos veían siempre el cine yanqui en sus múltiples aventuras. Ella no quería más cinematógrafo que el americano” (218).

Progresivamente, el cine hollywoodense introduce en esta niña santiaguina nuevas costumbres que no entraban en su acervo habitual: "El cine le servía para todo: de ayudamemoria, para hacer comparaciones y guiar sus gustos.” (219) Despidió a un pretendiente por no considerarlo lo suficientemente atlético, cambió sus hábitos para vestir, y finalmente, descuidó tanto sus labores en la casa que sus patrones hubieron de despedirla. Asi, ellos le cuentan al cronista:

no hubo más remedio que echarla. Nosotros no podemos pagar una criada fantástica... La casa era una película, pero ni siquiera de aquellas que trastornaron a Rosa, sino de Chaplin... iTodo patas arriba, sucio; la vajilla quebrada y el piso con mapamundis de mugre! (220)

La influencia concreta que la 'ciudad imaginaria' cinematográfica tiene sobre la 'ciudad real' provoca que se desdibujen los límites entre ambas; así, la casa deviene en un espacio de "película", se vuelve precaria y frágil, aparece "patas arriba" y "sucia". La mirada que "con ojos escrutadores" la niña hace sobre sí, se aplica, desde las idealizadas tierras de la azul Norteamérica, sobre la casa santiaguina misma.

Esta intervención que los imaginarios cinematográficos ejecutan sobre la ciudad real se acentúa en el último tramo de la historia. En él, el cronista decide visitar a Rosa, que ahora vive en un conventillo, para llevarle su enigmática carta. Llega así a una zona umbral del entramado urbano: "La cité o conventillo estaba en la parte extrema de la calle Gálvez, ahí donde Santiago se junta con el basural que lo circunda” (Edwards Bello 220). Allí vive la niña:

[1]a habitación era un hoyo, una de tantas cuevas disfrazadas donde vive nuestro bajo pueblo. Se respiraba un olor pesado de humo y comida ordinaria; donde debían existir cristales veíanse amarillentos periódicos; el techo mostraba grandes constelaciones de estiércol de mosca. Pero los agujeros y las manchas de las paredes estaban cubiertos con fotograbados y afiches en colores, tal como nos lo figuramos. Era una curiosa colección de retratos grandes y chicos de héroes y heroínas de cine norteamericano. Junto a la mirada picaresca y la boquita coqueta de Stewart, los grandes ojos ingenuos de Mabel y la estupenda cabellera de Mary Mac-Lean [...] al centro una bella tricromía, conseguida quién sabe como, representaba a Fairbanks en Arizona (221).

Rosa cubre la miseria de su hogar mediante un burdo ejercicio de tapizado: las fotos de las estrellas se vuelven un telón de fondo descascarado, que busca emular el "cuento azul" de Norteamérica. La casa se per-vierte en cuanto signo que es reescrito sin que se consideren sus posibilidades reales (sus vacíos), se vuelve ridícula como una palabra mal elegida. Así, la patética escena de la "cité" contrapone el "estiércol de mosca", el "olor del humo", y los 
"amarillentos periódicos", a la "mirada picaresca”, la "boquita coqueta" y los "grandes ojos ingenuos" de las estrellas, no preparados para gustar o mirar el paisaje que cubren.

El narrador cierra el cuadro relatando su encuentro con Rosa: incapaz de empañar "el cristal de su sueño" (221), se presentó a ella como un "combol" de Norteamérica que venía a dejarle su carta. A esas alturas la niña soñadora ya estaba decidida a comenzar un viaje imaginario: "En Chile no se podía vivir. Guardaba dinero y tenía un arca llena de 'joyas' para irse a Nueva York. Pero en Chile no concedían valor a sus joyas. Había escrito a muchos norteamericanos. Ansiaba llegar a América de cualquier manera [...] Aquí no se puede vivir, añadió” (222). La 'farsa' santiaguina también es descubierta por esta niña que, como el Quijote, mantiene su dosis de cordura. La crónica se resuelve así en una feroz contraposición entre el Santiago de los conventillos, el estiércol y la miseria, y una Norteamérica "azul" que sin embargo no existe: es la tierra idealizada de los espectadores ingenuos. La superposición entre la ciudad imaginaria y la ciudad real descubre una urbe precaria, sucia, cubierta, mísera: una ciudad que se quiere otra.

En cuanto publicación contingente, esta crónica nos demuestra que la fascinación de Rosa por las estrellas hollywoodenses no era, para 1921, un fenómeno aislado. Esto se constata gracias a un gesto que no pasa desapercibido al lector: la narración no resuelve el nudo principal, esto es, qué ocurrió con la entrega de la carta, y si esta era realmente de Douglas Fairbanks para la niña. Mediante este truco, Edwards Bello reconoce en sus lectores a otros espectadores que, evidentemente, conocerán a Douglas Fairbanks, y más aún, se sentirán identificados con la suerte de la protagonista. Así, "La visita del cowboy" también nos ilustra sobre sus receptores inmediatos, que probablemente fueron otros deslumbrados por la posibilidad imposible del sueño norteamericano y que quizás, en la lectura de esta historia, corroboraron sus ideas sobre las carencias de Santiago.

\section{Consideraciones finales}

la sala cinematográfica (de tipo común) es un lugar de disponibilidad, y es esa disponibilidad (mayor que en el ligue), la ociosidad del cuerpo, lo que mejor define el erotismo moderno, no el de la publicidad o el strip-tease, sino el de la gran ciudad

Roland Barthes

El itinerario que se traza al recorrer discursivamente la ciudad pasada que, como imaginaba Freud en El malestar en la cultura, se superpone a la ciudad presente que hoy vivimos y andamos, permite al analista reenlazarse a ella según la misma suerte de "erotismo moderno" que invade al espectador de cine y al flaneur urbano. Por lo mismo, la elaboración de una constelación imaginaria de textos literarios que, a fin de rastrear las huellas urbanas de la emergencia del cine en Santiago, articula los exponentes que se sitúan en la otra orilla 
de la vanguardia, se analoga a esa algo incómoda poética del andar a ras de suelo que, según escribió De Certeau, permite inaugurar discursivamente nuevos pasajes, recovecos y atajos que re-escriben la ciudad. Luego de este paseo por los lugares del cine, se puede volver a observar desde la altura el horizonte que nos entrega el análisis de los textos literarios. Así, en todas las obras se pudo constatar que la ciudad vista desde el paradigma cosmopolita del cine se descubre no como una ciudad estática, sino como tremendamente dinámica en sus carencias. Esto pues el fenómeno del cine y las "ciudades imaginarias" que este integra al acervo simbólico santiaguino permiten a sus habitantes re-conocerse a sí mismos como sujetos urbanos, esto es, como ejecutores de unas ciertas prácticas y poseedores de un lugar determinado en las dinámicas que se desarrollan en el contexto de transformaciones de la modernidad.

El motivo foráneo del cine, como nueva palestra desde la cual observar los procesos locales, funciona como eje re-ordenador de las dinámicas que cada texto despliega y por lo tanto nos habla de la ampliación del espectro simbólico santiaguino, en el que discursos en retirada se entrecruzan con discursos en advenimiento. En ambos textos se da voz a nuevos sectores sociales (las viejas, el roto) que en su capacidad de enunciar la ciudad de Santiago la rearticulan discursivamente, la integran antes aún que lo hicieran las reformas urbanas de 1927. Por lo tanto, puede concluirse que el cine, como fenómeno cosmopolita, fue uno de los actores fundamentales que promovió la integración de la ciudad de Santiago y las nuevas representaciones de sus devenires 'posibles', pues creó un espacio público común de carencias y reconocimientos; espacio público que es el que vemos enunciado precisamente en los textos estudiados.

La revisión de distintos textos literarios desde el paradigma cinematográfico se descubre, así, como una forma de poner en duda la vigencia de ciertos paradigmas representacionales vigentes, de explicitarlos precisamente en los períodos de transición, crisis o cambios, en los que el análisis intermedial es particularmente fecundo. Así, en Casa Grande, el análisis cinematográfico descubre el resquebrajamiento de las novelas fundacionales y las discursividades que en ellas se despliegan, presentándonos estas fisuras que prefiguran cambios de paradigma literario y también cultural y social. El doblaje cinematográfico entre Gabriela y Nelly y la cámara que significativamente enmarca el beso entre Ángel y Gabriela, entre otros, dejan de entrevisto nuevos paradigmas representacionales que comienzan a aparecer y a transmutar los relatos tradicionales. O, por otro lado, en el caso del roto, el paseo que inaugura el personaje en su recorrido urbano por los cines quiebra con la disposición "discursiva” tradicional que establece el binarismo entre la ciudad oficial y la ciudad no oficial. Textos trastocados, híbridos, en desfase, Casa Grande como novela naturalista anacrónica, la serie "Un roto va al cine" como crónica cinematográfica y "La visita del cowboy" como crónica de cine escriben estas ambigüedades cinematográficas y urbanas desde el terreno siempre fértil de la literatura. 


\section{Referencias}

Almandoz, Arturo. “Consideraciones preliminares". En La ciudad en el imaginario venezolano. Tomo I: Del tiempo de Maricastaña a la masificación de los techos rojos. Caracas: Fundación para la cultura urbana, 2002. Medio impreso.

Bongers, Wolfgang. "El cine y su llegada a Chile: conceptos y discursos". Taller de Letras 46 (2010). Medio impreso.

Bongers, Wolfgang, María José Torrealba y Ximena Vergara (eds.). Archivos i letrados: escritos sobre cine en Chile: 1908-1940. Santiago: Cuarto Propio, 2011. Medio impreso.

Burke, Peter. ¿Qué es la historia cultural? Barcelona: Paidós, 2006. Medio impreso.

Edwards Bello, Joaquín. Crónicas reunidas (I) 1921-1925. Santiago: Ediciones Universidad Diego Portales, 2008. Medio impreso.

Faúndez, Pablo. "El cine en las letras chilenas de principios de siglo: otra discusión sobre la vanguardia” Taller de Letras 46 (2010). Medio impreso.

Guerra, Lucía. “Prólogo”. Casa Grande. Santiago: Ayacucho, 2005. Medio impreso.

Lorenzini, Javiera. "Huellas, umbrales y ciudades posibles: el fenómeno cinematográfico en Santiago". Bifurcaciones 11 (2012). <http://www.bifurcaciones.cl>. Sitio web.

Orrego Luco, Luis. Casa Grande. Santiago: Andrés Bello, 1983. Medio impreso.

Ossandón B. Carlos y Eduardo Santa Cruz. El estallido de las formas. Chile en los albores de la "cultura de masas". Santiago: LOM, 2005. Medio impreso.

Ramos, Julio. Desencuentros de la modernidad en América Latina. Santiago: Cuarto Propio, 2003. Medio impreso.

Sommer, Doris. "Romance irresistible" Ficciones fundacionales: las novelas nacionales de América Latina. Colombia: Ediciones Fondo de la cultura económica, 2004. Medio impreso.

Subercaseaux, Bernardo. Historia de las ideas y de la cultura en Chile. Tomo III. Genealogía de las vanguardias. Santiago: Editorial Universitaria, 2004. Medio impreso.

---. Historia de las ideas y de la cultura en Chile. Tomo VI. Nacionalismo y cultura. Santiago: Editorial Universitaria, 2004. Medio impreso.

Vargas Keith, Consuelo. Los dos teatros: manifestaciones y discursos intermediales en revistas de cine y teatro en Chile en los inicios del siglo XX. Tesis de magíster en literatura, Universidad Católica de Chile, 2011. Inédito.

Recibido: 11 marzo 2103

Aceptado: 14 mayo 2013 